\title{
Long-Term Maintenance of the Functional Changes Induced by Influenza A Virus and/or LPS in Human Endothelial ECV-304 Cell Sublines
}

\author{
S. S. Smirnova ${ }^{a}$ *, M. M. Pisareva ${ }^{b}$, T. D. Smirnova ${ }^{b}$, K. V. Sivak ${ }^{b}$, and K. V. Vorobiev ${ }^{a}$ \\ ${ }^{a}$ Peter the Great St. Petersburg Polytechnic University, St. Petersburg, 195251 Russia \\ ${ }^{b}$ Smorodintsev Research Institute of Influenza, Ministry of Healthcare of the Russian Federation, St. Petersburg, 197376 Russia \\ *e-mail:sm.svetlana.s@gmail.com
}

Received September 24, 2018; revised December 16, 2018; accepted December 25, 2018

\begin{abstract}
Influenza A virus and secondary bacterial infection may have remote effects in the form of cardiovascular complications or fibrosis in different organs. However, the mechanisms governing the development of complications remain poorly studied. The present work reports the comparative assessment of the functional changes which take place in human ECV-304 endothelial cell sublines obtained previously by the longterm culturing of cells after exposure to varying infectious doses (IDs) of influenza A virus, and/or bacterial lipopolysaccharide (LPS). It has been demonstrated that, in the course of long-term culturing (six passages) after exposure to pathogenic agents (influenza virus and/or LPS), endothelial cells maintain changes in their migratory activity, permeability, and expression of mRNA for cytokines TNF $\alpha$ and TGF $\beta$ (along with the changes in their proliferation activity, which has been demonstrated earlier). The pattern of changes depended on the type of the agent (agents) to which the cells were exposed. The differences in migratory activity (which was at its maximum $4 \mathrm{~h}$ after wounding) between the cell sublines at the sixth passage correlated with the differences in their proliferation activity at the first passage (proliferation data were obtained previously). In particular, an increase in migration and proliferation was observed in the sublines exposed to low virus doses (ECV-1ID), as well as exposed to LPS (ECV-LPS), while the suppression of migration and proliferation was observed in the subline exposed to high virus doses (ECV-1000ID). In the ECV-1ID, ECV-LPS, and most notably in ECV-1ID + LPS sublines, we detected an increase in the expression of mRNA for cytokines TNF $\alpha$ and TGF $\beta$, which, however, didn't lead to the induction of apoptosis. We have also demonstrated an increase in cell permeability in the analyzed sublines, which was indicated by a decrease in the expression of the mRNAs for the genes encoding occludin and ZO-1, the tight junctions proteins. This paper also reports an evaluation of the effects of the antiviral preparations rimantadine and alpisarin on the functional state of cell sublines. As a result, it has been demonstrated that these drugs may be able to prevent the development of the pathological changes caused by influenza A virus and/or LPS in endothelial cells. The results obtained in the present work may be of use when studying the mechanisms of development of the influenza A virus and secondary bacterial infection complications.
\end{abstract}

Keywords: ECV-304 endothelial cell line, lipopolysaccharide (LPS), influenza A virus, cell migration, permeability

DOI: $10.1134 / \mathrm{S} 1990519 X 19040084$

\section{INTRODUCTION}

Endothelial cells form a semipermeable barrier between circulating liquid and the surrounding tissues. Changes in the endothelial barrier function contribute significantly to the development of different pathological states including inflammation and impaired wound sealing. Moreover, they may contribute to the

Abbreviations: ROS-reactive oxygen species, ID-infective dose, LPS-lipopolysaccharide, MOI-multiplicity of infection, FBS-fetal bovine serum, AJ-adherence junctions, CLDN5-claudin-5, OCLD-occludin, TGF $\beta$-transforming growth factor beta, TJ-tight junctions, TNF $\alpha$-tumor necrosis factor alpha, VEGF-vascular endothelial growth factor. development of acute encephalopathies and organ dysfunctions (as a result of cardiovascular system involvement), organ fibrosis, increased angiogenesis, and oncogenesis (Di Pietro, 2016; You and Stallcup, 2017). Disruption of the endothelial barrier in the lungs (in particular, as a result of influenza virus or bacterial infection) may cause liquid to penetrate into alveoli, resulting in pulmonary edema and development of acute respiratory distress syndrome (ARDS) (Kwok et al., 2016). Impaired migration of endotheliocytes and changes in their proliferation and apoptotic activity, as well as altered cell permeability, are critical for the development of pathological states. 
The ability of endothelial cells to regenerate a damaged intravascular layer relies on the activation of migration of the cells most closely located to the wound, as well as on strengthening of their capacity to proliferate. The process of cell migration includes cell polarization, formation of protrusions in the direction of movement, and detachment and contraction of the posterior cell margin, which are associated with dynamic reorganization of the actin cytoskeleton and microtubules involving signaling molecules from the Rho family of small GTPases (Kasa et al., 2015).

Key physiological regulators of intracellular signaling pathways in endothelial cells are represented by reactive oxygen and nitrogen species (BretonRomero, Lamas, 2014). Endogenous hydrogen peroxide $\left(\mathrm{H}_{2} \mathrm{O}_{2}\right)$ accumulates in actively migrating endothelial cells at the site of injury caused by the inflammation inducers of different type, in particular, of bacterial or viral nature. The main source of reactive oxygen species (ROS) are Nox NAD(P)H oxidases. Endothelial cells are rich in Nox2 and its homolog Nox4 (Basuroy et al., 2009). A particularly important role in the stimulation of the signaling systems associated with endothelial cell migration is played by the vascular endothelium growth factor (VEGF) which interacts with ROS produced not only in the cytosol by Nox2 and Nox4, but also in mitochondria (Kim et al., 2017).

Endothelial barrier is controlled by the locally produced vasoactive agents, such as histamine, prostaglandin, thrombin, and VEGF. They modulate cell membrane permeability by promoting dynamic changes in adherens (AJ) and tight junctions (TJ), and regulate the centripetal cell tension as a result of the cortical actin layer reorganization and formation of actomyosin stress fibers (Dejana et al., 2008; Kasa et al., 2015).

An increase in endothelial cell migration in the presence of bacterial lipopolysaccharide (LPS) is used as an indicator of the conversion of endothelial cells into activated fibroblasts via the endothelial to mesenchymal transition (Sarmiento et al., 2014).

Similarly to LPS, influenza virus is also able to trigger ROS production in epithelial and endothelial cells by means of Nox 2 and Nox4 induction, which may also facilitate the reproduction of the virus itself (Armatore et al., 2015). It has been demonstrated that the infection of endothelial cells with influenza virus leads to the disruption of intercellular contacts and a decrease in the content of claudin- 4 and claudin-5 (CLDN5) proteins that form part of TJs (Armstrong et al., 2012; Short et al., 2016).

Inflammatory response in the cells, induction of apoptosis, increase in cell permeability, and reorganization of cytoskeleton proteins are all performed by influenza A virus through the same cellular mechanisms and signaling pathways (Rho/ROCK, p38, and
JNK), which form part of the mechanism of action of LPS (Zhang et al., 2014; Liu et al., 2015).

The data presented above were obtained for in vivo acute viral infection or during the early period (12$24 \mathrm{~h}$ ) after the exposure to LPS or high infectious doses (IDs) of influenza A virus in vitro. However, we haven't found any data on the effects of simultaneous exposure of cell cultures to influenza virus and LPS.

Earlier, we have for the first time demonstrated an increase in proliferation of the influenza virusinfected human ECV-304 endothelial cells, which are nonpermissive for the influenza virus, with the decrease in the virus ID for 3-5 days after the infection, which was accompanied by an increase in cell apoptosis. Normal reproduction of influenza virus is impaired in nonpermissive cells, and the presence of virus is detected only at the level of the viral surface protein mRNA during no more than one or two passages (Danilenko et al., 2016). The change in the physiological state of the cells at the first passage (3-5 days) was the first stage in the changes induced in the cells by influenza virus, with further cell culturing (passages 3 to 8 ) resulting in the stably increased proliferation at low apoptosis levels (Smirnova et al., 2018).

The aim of the current work was to find a link between the primary exposure of ECV-304 cells to the agents (high and low influenza virus IDs and/or LPS) and the pattern of remote functional changes in the ECV-304 cell sublines at the sixth passage after the exposure. We have analyzed the changes in the migratory activity of the cells and gene expression at mRNA level, including the genes encoding tumor necrosis factor alpha $(T N F \alpha)$, transforming growth factor beta $(T G F \beta)$, and $N O X 4$, as well as the proteins forming part of TJ and controlling the permeability of cell membranes, $C L D N 5$, occludin $(O C L D)$, and $Z O-1$. Additionally, we assessed the correlation between the functional changes and the proliferation activity and apoptosis in cells of sublines that were analyzed previously (Smirnova et al., 2018), as well as evaluating the ability of rimantadine and alpisarin antiviral preparations to restore the normal functioning of endothelial cells.

\section{MATERIALS AND METHODS}

Sublines of the passaged human endothelium ECV304 cell line obtained after the infection with the influenza A virus Brisbane/10/07 (H3N2) were used in the work. Cells were infected with the low virus dose (1 ID) corresponding to the multiplicity of infection (MOI) equal to 0.000001 or high virus dose (1000 ID, MOI $=0.001$ ) and additionally (or exclusively) exposed to $100 \mathrm{ng} / \mathrm{mL}$ of the Escherichia coli LPS (Sigma, United States). Cell were passaged on the sixth to seventh day after infection by splitting them in a ratio of $1: 3$ using the alpha-MEM medium (Biolot, 
Table 1. Nucleotide sequences of primers and TaqMan probes used to analyze mRNA expression for the genes encoding cytokines, tight junction proteins, and other cellular factors

\begin{tabular}{|c|c|c|c|}
\hline Gene & Forward primer $5^{\prime}-3^{\prime}$ & Probe $5^{\prime}-3^{\prime}$ & Reverse primer $5^{\prime}-3^{\prime}$ \\
\hline$T N F \alpha$ & ACTTTGGAGTGATCGGCC & $\begin{array}{l}\text { ROX-CGAACCCCGAGTGA- } \\
\text { CAAGCCT-BHQ2 }\end{array}$ & $\begin{array}{l}\text { GCTTGAGGGTTTGCTA- } \\
\text { CAAC }\end{array}$ \\
\hline$T G F \beta$ & TGAGGGCTTTCGCCTTAGC & $\begin{array}{l}\text { HEX-CTCCTGTGACAGCAGG- } \\
\text { GATAACACACTGC-BHQ1 }\end{array}$ & $\begin{array}{l}\text { CGGTAGTGAACCCGTT- } \\
\text { GATGT }\end{array}$ \\
\hline NOX4 & CTGGACCTTTGTGCCTGTACTG & $\begin{array}{l}\text { ROX-AGCAATAAGCCAGTCAC- } \\
\text { CATCATTTCGGTC-BHQ2 }\end{array}$ & $\begin{array}{l}\text { ACCATTCGGATTTCCATG- } \\
\text { ACA }\end{array}$ \\
\hline$C L D N 5$ & CTGGTCTTTACTCCATCG & $\begin{array}{l}\text { ROX-ACTCCCGCCCTCTCT- } \\
\text { CAA-BHQ2 }\end{array}$ & AGCAGATTCTTAGCCTTC \\
\hline$O C L D$ & ACAAGAGCTTACAATCAGA & $\begin{array}{l}\text { HEX-TGTATTCATCAGCAGCAG- } \\
\text { CCAT-BHQ1 }\end{array}$ & СTTCACTTGCTTCAGTCT \\
\hline$Z O-1$ & GCTACGCTATTGAATGTC & $\begin{array}{l}\text { HEX-TCCACTCTGCTAATG- } \\
\text { CCTCTG-BHQ1 }\end{array}$ & GTGATCGACCAGAATGAT \\
\hline$A C T B$ & TCTACAATGAGCTGCGTGTGGCTCCC & $\begin{array}{l}\text { CY5-CAAGGCCAACCGC- } \\
\text { GAGAAGATGACCCAGATCAT- } \\
\text { BHQ2 }\end{array}$ & $\begin{array}{l}\text { AGCAACGTACATGGCTG- } \\
\text { GGGTGTTGAA }\end{array}$ \\
\hline
\end{tabular}

Russia) containing $1 \%$ fetal bovine serum (FBS) (HyClone, United States) without antibiotics. To detach cells from the surface, a solution containing vercene and chymopsin was used. Both control (intact) and experimental cells were at the sixth passage after the exposure to the agents (Smirnova et al., 2018). Depending on the agent (virus and corresponding ID, LPS, or virus and LPS together), the cell sublines were given the following names: ECV-1ID, ECV1000ID, ECV-LPS, ECV-1ID + LPS, and ECV1000ID + LPS.

Assessment of migratory activity. Cell suspensions of the corresponding sublines were inoculated into the wells of six-well plates (Nunc, Denmark) in a concentration of $7 \times 10^{4}$ cells $/ \mathrm{mL}(4 \mathrm{~mL}$ per well) in the alpha-MEM medium with $1 \%$ FBS, and the plates were placed into the $\mathrm{CO}_{2}$ incubator $\left(37^{\circ} \mathrm{C}\right.$ and $5 \%$ $\mathrm{CO}_{2}$ ). The next day, the cell monolayer was scratched with a $200-\mu \mathrm{L}$ tip, cells were washed with serum-free medium, and alpha-MEM medium with $1 \%$ FBS was added to the cells. An amount of $0.4 \mathrm{~mL}$ (1/10 medium volume) of tenfold solutions of each of the two analyzed antiviral preparation were applied into the wells. Immediately after the application of the antiviral preparations (point zero) and then $4,8,12$, and $24 \mathrm{~h}$ after the application, the selected region of the wound surface was imaged using the Axio Vert A1 microscope (Carl Zeiss, Germany) with $10 \times$ magnification. With the aid of the AxioVision Rel. 4.8 software, the wound surface area was calculated in the obtained images, and the change in the surface area with time, i.e., wound sealing, was determined. The end result was expressed as a percentage relative to the change in the wound surface area in the control samples (which were not subjected to infection and treated with antiviral drugs) at each time point.

Analysis of gene expression. On the fourth day after wounding (when the wound was almost completely sealed), cells were removed from the well surface, counted, washed with the serum-free medium, centrifuged, and used to assess the changes in the expression of the genes encoding cytokines and other cellular factors by real-time PCR. RNA was isolated from the analyzed samples using the AmpliPraim RIBO-prep kit (Central Research Institute of Epidemiology, Russia) according to the manufacturer's instructions. To assess gene expression, cDNA was synthesized on the RNA template in reverse transcription reaction using the Reverta-L kit (Central Research Institute of Epidemiology, Russia). Amplification reaction was carried out in the Rotor-Gene 6000 thermal cycler (Corbett Research, Australia) according to the following program: denaturation at $95^{\circ} \mathrm{C}$ for $10 \mathrm{~min}, 40$ cycles including $95^{\circ} \mathrm{C}$ for $20 \mathrm{~s}$, then $57^{\circ} \mathrm{C}$ for $40 \mathrm{~s}$, and $72^{\circ} \mathrm{C}$ for $20 \mathrm{~s}$, each. The reaction mixture contained $5 \mu \mathrm{L}$ of DNA, An amount of $10 \mu \mathrm{L}$ of ready-made $2.5 \times$ PCR buffer (Sintol, Russia), $0.5 \mu \mathrm{L}$ of SynTaq DNA polymerase $(5 \mathrm{U} / \mu \mathrm{L})$, and $0.5 \mu \mathrm{L}$ of each primer and probe $(10 \mathrm{pmol} / \mu \mathrm{L})$ (DNA-Sintez, Russia) in $25 \mu \mathrm{L}$. Primer for the actin gene $(A C T B)$ were used as an internal standard. The nucleotide sequences of the oligonucleotide primers and probes for $T N F \alpha, T G F \beta, N O X 4$, $C L D N 5, O C L D, Z O-1$, and $A C T B$ are provided in Table 1. Expression levels were determined for two or three times, and the end result was expressed in relative units, indicating a change in gene expression relative to the control, and calculated according to the for- 
mula $2^{-\Delta \Delta C t}$, where $C_{t}$ is the cycle threshold value for the analyzed sample (Wong and Medrano, 2005).

Rimantadine (Sigma, Germany) and alpisarin (AllRussia Research Institute of Medicinal and Aromatic Plants, Russia) solutions were prepared using serumfree alpha-MEM medium and were used in final concentrations of $20 \mu \mathrm{g} / \mathrm{mL}$ and $50 \mu \mathrm{g} / \mathrm{mL}$, respectively.

At each time point, two wells were analyzed. Experiments were performed not less than in triplicates.

Statistical data analysis was performed using the Mann-Whitney U test for the comparison of the two groups of nonparametric samplings. Differences were considered significant with $P<0.05$.

\section{RESULTS}

Analysis of cell migration was performed using the previously obtained ECV-304 cell sublines (Smirnova et al., 2018) at the sixth passage after the exposure to influenza virus and/or LPS treatment. Migratory activity was assessed by the change in wound surface area with time (wound sealing). As a result, we have demonstrated that the maximum migratory activity is observed in all cell sublines (compared to the control intact cells) during the first $4 \mathrm{~h}$ (here and in what follows, time is given in hours after wounding). Cell migration grew slower by the 8th-12th hours and remained almost at the 12-h and control levels up to the 24th hours (Fig. 1a). The comparison of different sublines showed that highest migratory activity was exhibited by the endothelial cells after the contact with the minimum infective dose of influenza $A$ virus (ECV-1ID subline, migratory activity $141 \%$ of the control activity $4 \mathrm{~h}$ after wounding). The migration exhibited by the cells infected with the high virus dose (ECV-1000ID) was the minimum (54\% of the control $4 \mathrm{~h}$ after wounding). The cells after the contact with LPS (both in the case of individual exposure and together with the virus) showed slightly increased migratory activity during the first hours after wounding (4-8 h), while later migration remained at the control level (Fig. 1a).

To assess the effects of the antiviral preparations (rimantadine and alpisarin) on the migratory activity of the cells, the preparations were applied to the wells containing cells immediately after wounding. As a result, it was demonstrated that they significantly affect cell migration. Rimantadine decreased the migratory activity of the control cells by $73 \% 4 \mathrm{~h}$ after wounding, while alpisarin decreased it by $67 \%$; however, migration was restored to the control level $8 \mathrm{~h}$ after wounding. Rimantadine had almost no effect on the migration of the ECV-1ID subline cells (148\% in $4 \mathrm{~h}$ ), while the level of ECV-1000ID subline cell migration in the presence of this drug grew higher than the control level (up to $123 \%$ in $4 \mathrm{~h}$ ). Alpisarin caused even higher increase in the migratory activity of these subline cells in $4 \mathrm{~h}$ (up to $200 \%$ in ECV-1ID subline and up to $147 \%$ in the ECV-1000ID subline). The highest increase in cell migration was caused by both preparations in the sublines treated with LPS, namely, ECV-LPS (up to $238 \%$ in the case of rimantadine and $219 \%$ in the case of alpisarin), ECV-1ID + LPS (219 and $204 \%$, respectively), and ECV-1000ID + LPS (197 and 175\%, respectively). In all the sublines, maximum migration level in the presence of the antivirals was also observed $4 \mathrm{~h}$ after wounding, together with a decrease in the level of migration by eighth hour; however, in this case, migratory activity remained higher than in the control (Fig. 1a).

We have also revealed that the pattern of differences in the migratory activity between the cell sublines at the sixth passage at the maximum activity point ( $4 \mathrm{~h}$ after wounding) correlated with the pattern of changes in proliferation activity of the cells at the first passage (proliferation data were obtained previously (Smirnova et al., 2018)). In particular, the enhancement of cell migration and proliferation was observed in the ECV-1ID and ECV-LPS sublines, while enhancement of suppression was observed in the ECV-1000ID subline (Figs. 1b, 1c). Comparison of the migration and proliferation patterns for the cells at the sixth passage showed that the similarity was retained for most sublines, except for the ECV-LPS subline, in which proliferation activity decreased at the sixth passage, and the ECV-1000ID subline, in which, by contrast, an increase in proliferation was detected (Figs. 1b, 1c).

Therefore, the differences in the migratory activity of the cells in the analyzed sublines at the sixth passage are determined by the initial (at the first passage) effects of the agents (high or low doses of the virus and/or LPS).

On the fourth day after wounding (when the wound was almost completely sealed), the analyzed subline cells were detached from the surface of the six-well plates and used to determine the expression levels of mRNAs for cytokines (TNF $\alpha$ and TGF $\beta$ ), NOX4 oxidase, and TJ proteins (OCLD, ZO-1, and CLDN5) (ECV-1000ID and ECV-1000ID + LPS sublines were not used).

PCR has revealed an increased expression of mRNAs for the cytokines TNF $\alpha$ and TGF $\beta$ in the cells that were exposed to the virus and/or LPS, with the highest level of expression for these cytokines having been observed in the ECV-1ID + LPS subline cells (46 and 19 times higher, respectively, than in the control). Treatment with the antiviral preparations rimantadine and alpisarin considerably decreased the expression of the mRNAs for these cytokines enhanced by the exposure to virus and/or LPS, although, rimantadine on its own stimulated the expression of $T N F \alpha$ mRNA (19 times higher than in the control) (Fig. 2). 


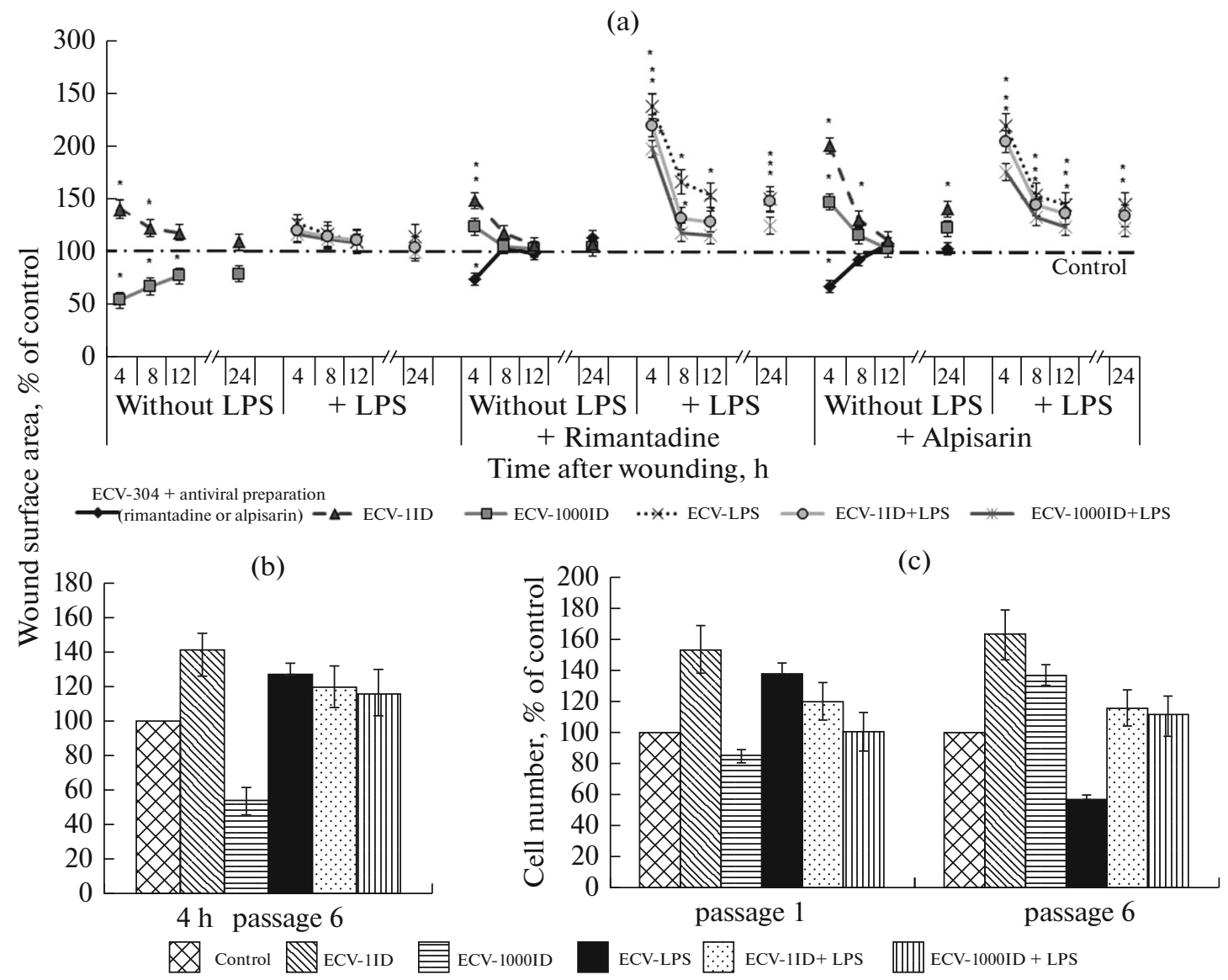

Fig. 1. Migratory (sixth passage) $(\mathrm{a}, \mathrm{b})$ and proliferation $(c$; first and sixth passages) activity of the ECV-304 cell sublines obtained by a one-time exposure to the influenza A virus Brisbane/10/07 (H3N2) and/or treatment with $100 \mathrm{ng} / \mathrm{mL}$ of $E$. coli lipopolysaccharide (LPS) at the first passage; effects of the antiviral preparations ( $20 \mu \mathrm{g} / \mathrm{mL}$ of rimantadine and $50 \mu \mathrm{g} / \mathrm{mL} \mathrm{of} \mathrm{alpisarin)}$ applied immediately after wounding at the sixth passage on the migratory activity of the ECV-304 cell sublines (a). Here and in what follows, ID is infectious dose, and the control is ECV-304 cells cultured in the medium without the addition of any agents. Depending on the agent used (virus ID, LPS, or virus and LPS together), cell sublines were given the following names: ECV-1ID, ECV-1000ID, ECV-LPS, ECV-1ID + LPS, and ECV-1000ID + LPS. Migratory activity was assessed by the change in the wound sealing area $4,8,12$, and $24 \mathrm{~h}$ after scraping. The results were expressed in $\%$ relative to the change in wound surface area in the control samples at each time point; asterisk indicates significant difference from the control with $P<0.05$. $c$ : data are taken from Smirnova et al., 2018.

A slight increase in the expression level of NOX4 mRNA was detected only in the ECV-1ID subline (1.4 times higher than in the control), while antiviral preparations reversed it to the control levels. The expression of the mRNA for the CLDN5 gene encoding the TJ protein was at the control level in all cell sublines except for ECV-1ID + LPS, in which CLDN5 mRNA expression was 2.5 times higher than in the control. The treatment with antiviral preparations increased mRNA expression level for the gene encoding this protein in all sublines, and especially so in the case of alpisarin (with the maximum increase-by 7.3 times-being in the ECV-LPS subline), which may indicate that cell permeability returns to its normal level (Fig. 2).

In a separate experiment, we assessed the expression levels of mRNAs for the genes encoding other proteins within the TJ family, namely, OCLD and $Z O-1$. The obtained results revealed that the expression level of mRNAs for these genes gradually decreased in ECV-304 cells from the first passage to the fifth passage after a single exposure to different doses of influenza A virus and/or LPS, this effect being clearer in the case of $O C L D$ than in the case of $Z O-1$ (Fig. 3). These data provide evidence that the exposure to influenza virus and/or LPS leads to an increase in the permeability of cell membranes, which is further maintained in the analyzed cell sublines for a long period of time.

\section{DISCUSSION}

Angiogenesis plays an important role in many physiological and pathological processes, while apoptosis serves as one of the regulatory factors of angiogenesis. The ability of the highly virulent avian influ- 


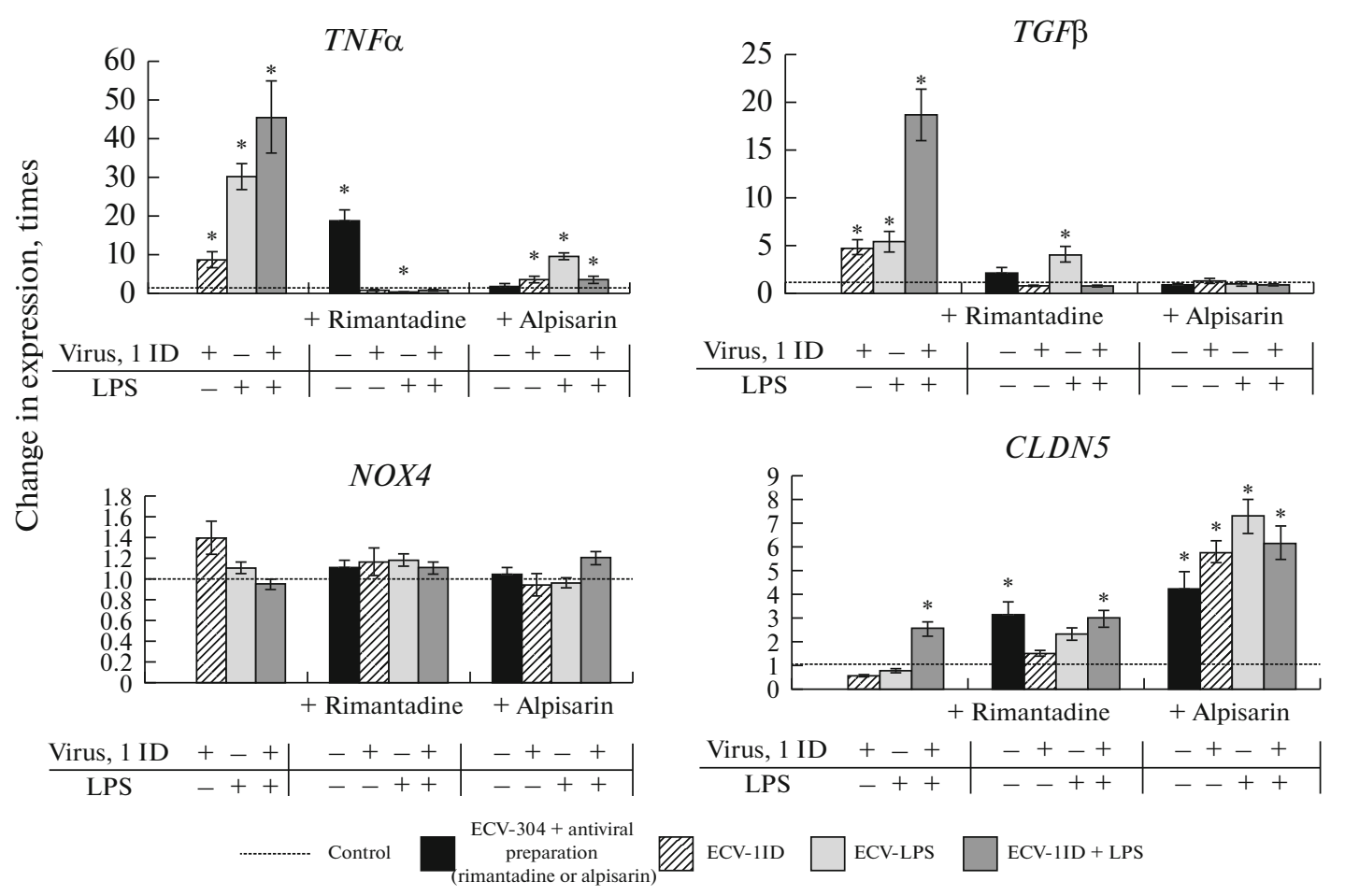

Fig. 2. Analysis of $T N F \alpha, T G F \beta, N O X 4$, and claudin-5 (CLDN5) gene expression in the ECV-304 cell sublines on day 4 of the sixth passage after complete wound sealing. Based on real-time PCR data. In Figs. 2 and 3, results are given in relative units representing the change in gene expression relative to the control that were calculated according to the formula $2^{-\Delta \Delta \mathrm{Ct}}$; control is taken as 1 .

enza virus strains to cause a lethal disease in chicken as a result of apoptosis of the endothelial cells in different organs is well-known (Swayne, 2007). However, the pathological mechanisms of influenza infection, in particular, the link between the infection and apoptosis and barrier function impairment, are not always clear. It has been demonstrated in vitro that human influenza A viruses are able to trigger TNF-induced apoptosis of endothelial cells (Sumikoshi et al., 2008). At the same time, increased cell permeability in human microvascular endothelium (HMVEC) and association with apoptosis has been demonstrated only for live (infectious) influenza A virus; UV-inactivated avirulent influenza virus also caused an increase in cell permeability, but in this case not as a result of apoptosis, but rather as a result of the degradation of the TJ protein CLDN-5 (Armstrong et al., 2012). The role of the cytokines TNF $\alpha$ and TGF $\beta$ in both apoptosis induction and cell barrier function impairment is well-known, although these processes often develop independently of each other (Petrache et al., 2001; van Meeteren and ten Dijke, 2012).

In our previous work, we have demonstrated very low levels of apoptosis, just as in control cells, in all the obtained endothelium cell sublines cultured during more than three passages (six passages, in particular). At the same time, the antiviral preparations rimanta- dine and alpisarin reduced the increased proliferation of the ECV-1ID subline cells at the sixth passage and simultaneously stimulated apoptosis in all the analyzed sublines (Smirnova et al., 2018).

The comparative study of the human endothelial ECV-304 cell sublines carried out in the present work and in our previous work (Smirnova et al., 2018) has demonstrated that the infection of nonpermissive cells with influenza A virus (both in high and in very low doses) and exposure to LPS can change migratory, proliferation, and apoptotic activity of cells and impair cell barrier function. We have shown for the first time that these functional changes may be observed during a long period of cell culturing after the exposure.

In the analyzed cell sublines, the expression of mRNA for $O C L D$ and $Z O-1$ encoding the proteins that form part of the TJ complex gradually decreased with an increase in the passage number, which indicated an increase in cell permeability (Kasa et al., 2015). The results obtained in the present work, as well as in the previous one (Smirnova et al., 2018), show that all sublines of endothelial cells acquire resistance to apoptosis in the process of culturing (after the third passage), notwithstanding the high level of expression of mRNA for both $T N F \alpha$ and $T G F \beta$, especially in the ECV-1ID + LPS subline. This indicates a link 


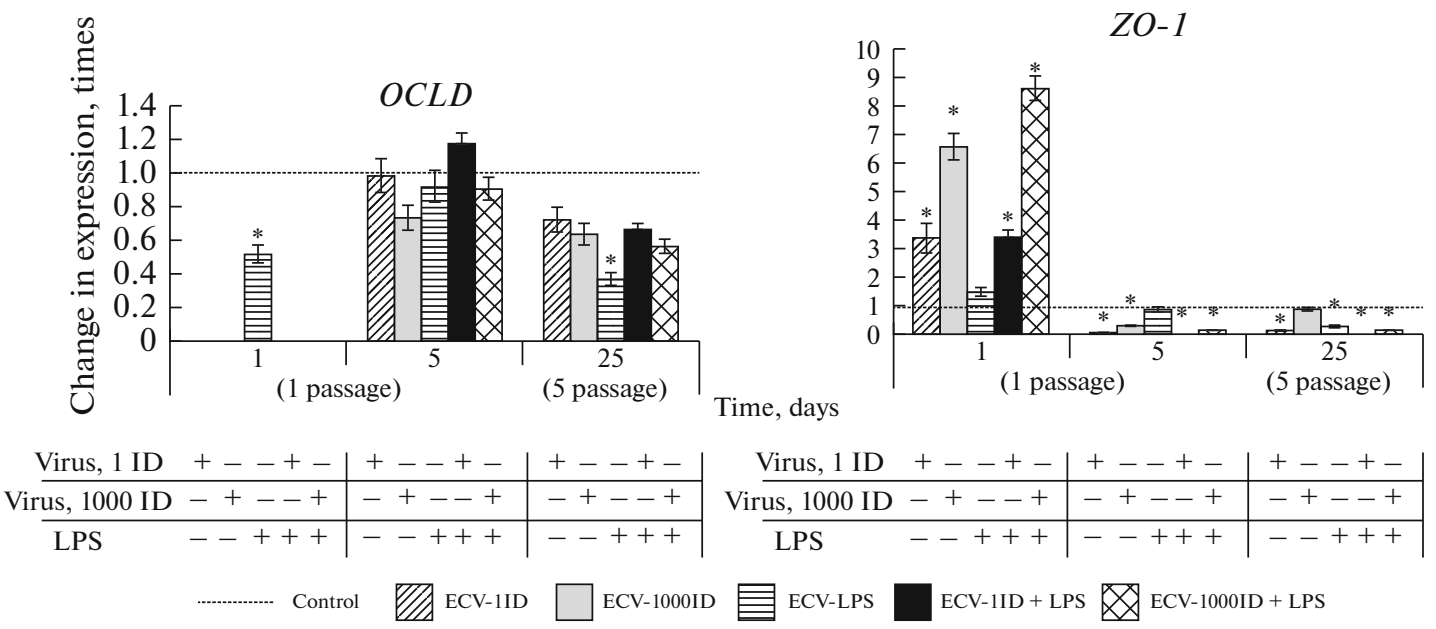

Fig. 3. Analysis of expression of the genes encoding the tight junction proteins occludin (OCLD) and $Z O-1$ in the ECV-304 cell sublines during the time period from the first to the fifth passage. Based on real-time PCR data.

between the cytokines TNF $\alpha$ and TGF $\beta$ and the increase in cell permeability, but not the induction of apoptosis in this case. This conclusion is supported also by the fact that, in the presence of the antivirals rimantadine and alpisarin, expression of $T N F \alpha$ and $T G F \beta$ genes is inhibited and cell permeability is restored (due to the increase in the CLDR5 mRNA expression) with a simultaneous increase in the apoptosis level, which also indicates that these drugs are capable of restoring the functional state of the cells.

It is characteristic that the level of NOX4 mRNA expression appeared to be only slightly increased and only in a single subline, which was obtained after the infection with the low dose of influenza virus (ECV1ID) and differed from all others in its increased proliferation level. This allows it to be suggested that the dysfunction of cells in the analyzed sublines that develops over the period of their long-term culturing may be caused by the increase in ROS content not only in the cytosol (produced by Nox 2 and Nox 4 oxidases), but, apparently, to a greater extent in mitochondria (Harel et al., 2017).

The multifunctional cytokine TGF $\beta$ can enhance cell proliferation and apoptosis resistance through the ALK5 Smad 2/3/NF- $\kappa$ B signaling pathway, which induces the transformation of endothelial cells into miofibroblasts (van Meeteren and ten Dijke, 2012; Montorfano et al., 2014). TGF $\beta$ is considered to be the key cytokine participating in fibrosis. Reduced sensitivity of lung fibroblasts to Fas-induced apoptosis (resistance to apoptosis) with increased alveolar epithelial cell apoptosis level is a characteristic feature of pulmonary fibrosis, in which the regions of a disrupted epithelial cell layer with reduced reparation capacity are filled with apoptosis-resistant fibroblasts (Maher et al., 2010; Liu and Desai, 2015). Our findings (increased expression level for TGF $\beta$ mRNA along with the development of apoptosis resistance) provide support for the idea that there is a link between influenza virus infection and, especially, LPS treatment with myofibroblast formation and the possibility of pulmonary fibrosis development. Thus, the addition of LPS at the time of ECV-304 cell infection with influenza A virus leads to a more serious dysfunction of endothelial cells, in the same way as a secondary bacterial infection, even in the case of mild influenza infection leads to serious and, in many cases, complications that occur much later (McCullers, 2006).

Our data also indicate that endothelial cells infected only with influenza A virus may become atypical (demonstrate increased proliferation activity and an extremely low apoptosis level), which may facilitate the expansion of these cells and hinder the reparation of damaged blood vessel regions with normal endothelial cells. This may lead to enhanced angiogenesis, which in turn promotes oncogenesis, and may possibly cause intravascular lesions of unknown origin with the characteristics of pseudotumor hyperplasia (Diaz-Flores et al., 2017).

To summarize, the results of the present work have revealed that under our experimental conditions (the use of varying virus doses and/or LPS with subsequent long cell culturing), changes in endothelial cell functioning can be observed for a long period of time after the exposure. We have also demonstrated that there is a connection between the agent used (virus and/or LPS) and the direction of functional changes (increase or decrease) in migratory and proliferation activity and cell permeability. The antiviral preparations rimantadine and alpisarin have a substantial effect on all the analyzed live processes in the cell sublines, which indicates that these preparations may pre- 
vent pathological changes in the endothelial cells caused by influenza A virus and/or LPS.

The obtained results may be helpful in the search for the mechanisms of development of influenza and secondary bacterial infection complications.

\section{COMPLIANCE WITH ETHICAL STANDARDS}

The authors declare that they have no conflict of interest.

This article does not contain any studies involving animals or human participants performed by any of the authors.

\section{REFERENCES}

Amatore, D., Sgarbanti, R., Aquilano, K., Baidelli, S., Limonci, E., Civitelli, L., Nencioni, L., Garaci, E., Ciriolo, M.R., and Palamara, A.T., Influenza virus replication in lung epithelial cells depends on redox-sensitive pathways activated by NOX4-derived ROS, Cell. Microbiol., 2015, vol. 17, pp. 131-145.

Armstrong, S., Wang, Ch., Tigdi, J., Si, X., Dumpit, C., Charles, S., Gamage, A., Moraes, Th., and Warren, L., Influenza infects lung microvascular endothelium leading to microvascular leak: role of apoptosis and claudin-5, PLoS One, 2012, vol. 7, no. 10. e47323.

https://doi.org/10.1371/journal.pone.0047323

Basuroy, Sh., Bhattacharya, S., Charles, W., and Parfenova, H., Nox4 NADPH oxidase mediates oxidative stress and apoptosis caused by TNF-a in cerebral vascular endothelial cells, Am. J. Physiol. Cell Physiol., 2009, vol. 296, pp. 422-432.

Breton-Romero, R. and Lamas, S., Hydrogen peroxide signaling in vascular endothelial cells, Redox Biol., 2014, vol. 2, pp. 529-534.

Danilenko, D.M., Smirnova, S.S., Smirnova, T.D., Pisareva, M.M., Plotnikova, M.A., Drobintseva (Durnova), A.O., and Eropkin, M.Yu., Human lung carcinoma (A-549) continuing cell line and human endothelial (ECV-304) continuing cell line responses to the influenza virus at different multiplicities of infection, Cell Tissue Biol., 2016, vol. 58, no. 3, pp. 305-313.

Dejana, E., Orsenigo, F., and Lampugnani, M.G., The role of adherens junctions and VE-cadherin in the control of vascular permeability, J. Cell Sci., 2008, vol. 121, pp. 21152122.

Di Pietro, L., Angiogenesis and wound repair: when enough is enough, J. Leukocyte Biol., 2016, vol. 100, pp. 979-984.

Diaz-Flores, L., Gutierrez, R., Garcia-Suarez, M., Saez, F., Gutierrez, E., Villadares, F., Carrsco, J., DiazFlores, L., Jr., and Madrid, J., Morphofunctional basis of the different types of angiogenesis and formation of angiogenesis-related secondary structures, Histol. Histopathol., 2017, vol. 32, pp. 1239-1279.

Harel, S., Mayaki, D., Sanchez, V., and Hussain, S., NOX2, NOX4, and mitochondrial-derived reactive oxygen species contribute to angiopoietin- 1 signaling and angiogenic responses in endothelial cells, Vascul. Pharmacol., 2017, vol. 92, pp. 22-32.
Kasa, A., Csortos, C., and Verin, A.D., Cytoskeletal mechanisms regulating vascular endothelial barrier function in response to acute lung injury, Tissue Barriers, 2015, vol. 3. e974448.

https://doi.org/10.4161/21688370.2014.974448

Kim, Y., Kim, S., Tatsunami, R., Yamamura, H., Fukai, T., and Ushio-Fukai, M., ROS-induced ROS release orchestrated by Nox4, Nox2, and mitochondria in VEGF signaling and angiogenesis, Am. J. Physiol. Cell Physiol., 2017, vol. 312, pp. 749-764.

Kwok, H., Poon, P., Fok, S., Ying-Kit, Y., Mak, N., Chan, M., Peiris, J., and Wong, R., Anti-inflammatory effects in indirubin derivatives on influenza A virusinfected human pulmonary microvascular endothelial cells, Sci. Rep., 2016, vol. 6, pp. 18941-18953.

Liu, R.-M. and Desai, L., Reciprocal regulation of TGF-b and oxygen species: a perverse cycle of fibrosis, Redox Biol., 2015, vol. 6, pp. 565-577.

Liu, H., Yu, X., Yu, S., and Kou, J., Molecular mechanisms in lipopolysaccharide-induced pulmonary endothelial barrier dysfunction, Int. Immunopharmacol., 2015, vol. 29, pp. 937-946.

Maher, T., Evans, I., Bottoms, S., Mercer, P., Thorley, A., Nicholson, A., Laurent, G., Tetley, T., Chambers, R., and McAnulty, R., Diminished prostaglandin E2 contributes to the apoptosis paradox in idiopathic pulmonary fibrosis, Am. J. Respir. Crit. Care Med., 2010, vol. 182, pp. 73-82.

McCullers, J., Insights into interaction between influenza virus and pneumococcus, Clin. Microbiol. Rev., 2006, vol. 193, pp. 571-582.

Montorfano, I., Becerra, A., Cerro, R., Echeverria, C., Saez, E., Morales, M.G., Fernandez, R., Cabello-Verrugio, C., and Simon, F., Oxidative stress mediates the conversion of endothelial cells into myofibroblasts via a TGFb1 and TGF-b2-dependent pathway, Lab. Invest., 2014, pp. $1-15$.

Petrache, I., Verin, A., Crow, M., Birukova, A., Liu, F., and Garcia, J., Differential effect of MLC kinase in TNFa-induced endothelial cell apoptosis and barrier dysfunction, Am. J. Physiol. Lung Cell Mol. Physiol., 2001, vol. 280, pp. L1168-L1178.

Sarmiento, D., Montorfano, I., Caceres, M., Echeverria, C., Fernandez, R., Cabello-Verrugio, C., Cerda, O., Tapia, P., and Simon, F., Endotoxin-induced vascular endothelial cell migration is dependent on TLR4/NF-kB pathway, NAD(P)H oxidase activation, and transient receptor potential melastatin 7 calcium channel activity, Int. J. Biochem. Cell Biol., 2014, vol. 5, pp. 11-23.

Short, K.R., Kasper, J., van, der, Aa, S., Andewed, A.C., Zaaraoui-Boutahar, F., Goeijenbier, M., Richard, M., Herold, S., Becker, C., Scott, D.R., Limpens, R.W., Koster, A.J., Barcena, M., Foucher, R.A., Kirpatrick, C.J., and Kuiken, T., Influenza virus damages the alveolar barrier by disrupting epithelial cell tight junctions, Eur. Respir. J., 2016, vol. 47, pp. 954-966.

Smirnova, S.S., Smirnova, T.D., Sivak, K.V., and Vorobiev, K.V., Change in the functional state of cells of the human endothelial cell line ECV-304 under the influence of influenza A virus, lipopolysaccharide from $E$. coli, and some drugs, Tsitologiya, 2018, vol. 60, no. 4, pp. 287-296.

Sumikoshi, M, Hashimoto, K., Kawasaki, Y., Sakuma, H., Suzutani, T., Suzuki, H., and Hozoya, M., Human influ- 
enza virus infection and apoptosis induction in human vascular endothelial cells, J. Med. Virol., 2008, vol. 80, no. 6, pp. 1072-1078.

Swayne, D., Understanding the complex pathobiology of high pathogenicity avian influenza viruses in birds, Avian Dis., 2007, vol. 51, suppl. 1, pp. 242-249.

van Meeteren, L.A. and ten Dijke, P., Regulation of endothelial cell plasticity by TGF- $\beta$, Cell Tiss. Res., 2012, vol. 347, pp. 177-186.

Wong, M.L. and Medrano, J.F., Real-time PCR for mRNA quantitation, BioTechniques, 2005, vol. 39, pp. 75-85.
You, W. and Stallcup, W., Location of VEGF to vascular ECM is an important aspect of tumor angiogenesis, Cancers, 2017, vol. 9, pp. 97-111.

Zhang, Ch., Wu, Y., Xuan, Z., Zhang, Sh., Wang, X., Hao, Y., and Zhang, Sh., P38MAPK, Rho/ROCK and $\mathrm{PKC}$ pathway are involved in influenza-induced cytoskeletal rearrangement and hyperpermeability in PMVEC via phosphorylating ERM, Virus Res., 2014, vol. 192, pp. 6-15.

Translated by E. Martynova 